\title{
A Special Issue of Applied Magnetic Resonance in Honor of Professor Dr. Hans-Martin Vieth at the Occasion of his 70th Birthday
}

\section{Hans-Heinrich Limbach • Ernst Rössler • Alexandra Yurkovskaya}

Received: 9 September 2012/Published online: 6 October 2012

(C) Springer-Verlag Wien 2012

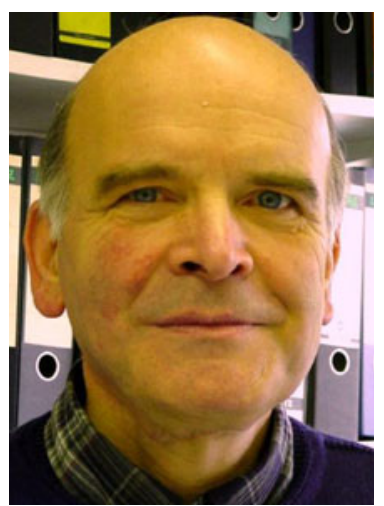

On 3rd October 2012 Hans-Martin Vieth, Professor of Physics at the Free University of Berlin, celebrated his 70th birthday. His friends and colleagues would like to honor this event with the present special issue of Applied Magnetic Resonance. The 24 articles are ordered according to the different research fields of Hans-Martin Vieth:

\section{H.-H. Limbach}

Institut für Chemie und Biochemie, Freie Universität Berlin, 14195 Berlin, Germany

\section{E. Rössler}

Universität Bayreuth, Lehrstuhl Experimentalphysik II, 95440 Bayreuth, Germany

A. Yurkovskaya ( $\square)$

International Tomography Center, 630090 Novosibirsk, Russia

e-mail: yurk@tomo.nsc.ru 
1. Magnetic Resonance Methodology (6 articles).

2. Structure and function of solids and materials (5 articles).

3. Structure and function of soft matter ( 5 articles).

4. Reaction dynamics and Hyperpolarization (8 articles).

We would like to thank all co-workers and friends of Hans-Martin Vieth who contributed to this issue. We also express deep gratitude to the editorial board of Applied Magnetic Resonance and also to the reviewers of the manuscripts for their continuous help and support.

Guest Editors: Hans-Heinrich Limbach, Ernst Rössler, Alexandra Yurkovskaya. 